\title{
Gendered performances and identity construction among UK fe- male soccer players and netballers: a comparative study
}

\author{
Tracey J. Devonport ${ }^{1 *}$ Kate Russell ${ }^{2}$ Kath Leflay ${ }^{1}$ Jennifer Conway ${ }^{1}$

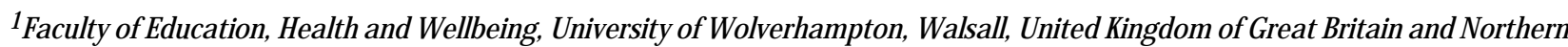 \\ Ireland; \\ ${ }^{2}$ School of Education and Lifelong Learning, University of East Anglia, Norwich, United Kingdom of Great Britain and Northern Ireland
}

*CONTACTTracey J. Devonport T.Devonport@wlv.ac.uk

\begin{abstract}
ABSTRACT

This paper examines the gendered performances and identity construction of UK female University soccer players and netballers $(n=31)$. Focus group interviews explored their sporting experiences with reference to body perceptions, and perceptions of their sporting bodies outside sporting contexts. Three themes resulted from data analysis, these being; (1) UKculture, body performances and femininity, (2) sporting culture, body performances and femininity and (3) transiency of body satisfaction across sport and nonsport contexts. Findings suggest that sport may not always provide an opportunity to challenge and resist dominant discourses. In both netball and soccer, a range of surveillance and management practices were used that served to perpetuate the value of a 'feminine' and assumed heterosexual body, and legitimize their sport participation through an emphasis on a hyper-femininity. The influence of sport subcultures on gendered performances and identity construction, along with implications for marketing sports participation to women are discussed.
\end{abstract}

KEYWORDS body image; body performance; masculine; feminine; transiency

\section{Background}

In 2005 the Football Association announced that women's soccer had overtaken netball as the most popular female sport in the UK. The Sport England 'Active People' survey of 2016 demonstrated that this trend appears to be continuing with a $16 \%$ increase in women's participation in soccer, and a comparative $2 \%$ increase in Netball participation (https:// www.sportengland.org/research/about-our-research/active-people-survey/). However, while clear that females are increasingly active in both soccer and netball, many studies have highlighted female athletes still experience gender role conflict whereby a female identity is perceived as contrasting expectations for an athletic identity (Cooky and McDonald 2005; Hardy 2015; Krane et al. 2004). Research suggests that females in 'masculine' sports (e.g. soccer) are more likely to experience gender role conflict than those in 'feminine' appropriate (e.g. netball) sports (Guillet et al. 2006; Hardy 2015). For instance, Cox and Thompson (2001) suggested that most female soccer players have been labelled in some way, often starting with being labelled as a tomboy during adolescence, but turning to terms such as butch, lesbian or dyke, all used derogatorily, upon reaching adulthood. Hermann and Vollmeyer (2016) illustrated the ways in which such negative stereotypes can limit women from achieving their potential in soccer and effect participation. In contrast, work by Fasting and Brackenridge (2009) comparing the experiences of female tennis players and female gymnasts highlighted that athletes in these sports did not experience negative labelling and questioning of their sexuality, perhaps due to a greater congruence of the requirements of the sport and femininity. Research focusing on netball has received comparatively little attention, but indicates that male hegemonic discourses of sport have been both reinforced and resisted by the recognition of netball as a suitable sport for women (Burroughs and Nauright 2000).

For sports that present incongruence with the societal requirements of femininity, this can result in the perception of athletic and feminine selves as separate entities for some women (Bennett et al. 2016). In the context of sport, female athletes may perceive the performance of the body (as functionally sport relevant) to be more important than its presentation (as feminine) (Bennett et al. 2016; Krane et al. 2004; Author). However, once out of the sporting environment and in social contexts, feminine identities are emphasized as a consequence of being appraised alongside social views of ideal bodies rather than sporting ones (Bennett et al. 2016; Author). Research indicates that this transiency in body 
image satisfaction and performance, is often attributable to females fearing that sport may lead their bodies to become too muscular or masculine (Choi 2000; Krane et al. 2004; Steinfeldt et al. 2011a). The muscularity required to excel in their sport, may exceed that deemed acceptable by society for females, thus exacerbating the conflict they are theorized to face (Steinfeldt et al. 2011a). Previous studies have identified many ways in which female athletes may seek to manage these fears, and emphasize their femininity. This includes: the use of clothing, makeup, and dieting to emphasize femininity (basketball), wearing of pony tails (soccer); make up or fringes on shorts (boxing); or wearing skirts as part of a dress code for post sporting performances (cricket) (Bennett et al. 2016; Caudwell 2003; Christopherson, Janning, and McConnell 2002; Cox and Thompson 2001; Halbert 1997; Ogunniyi 2013).

The present study, undertaken in a UK University setting, compares the experiences of female participants in two sports (soccer and netball), examining athlete's discursive testimonials and identity constructions. These sports were selected because of respective connotations of masculinity and femininity. Contrasting experiences of female participants in these sports will provide insight into the negotiations and management practices that occur when aligning gender identity and gendered performance to acceptable notions of gender and sexuality in the sport context, and the tensions evident in producing a body that is not the other.

For readers less familiar with netball as a sport, it was developed from women's basketball in the late nineteenth century and modified to reflect patriarchal ideas of 'a compliant femininity' (Taylor 2004, 126)AQ2. Essentially the contact nature of basketball was removed, a process described by Treagus (2005) as the de-masculinization of basketball to ensure that it fitted the dominant ideals of female physical activity at the time. While some aspects of the game have changed over the past century, netballs interpretation of femininity has also gone beyond contact to also include how athletes dress, their physicality and their behaviour (Taylor 2004). We would argue that this helps to construct very particular ways of identity categorization for netball players.

\section{Theoretical background}

The examination of gender identity and body performances is typically underpinned by the notion that women and men in society undergo processes of gender socialization, whereby they learn the respective gender norms and expectations of femininity and masculinity (Steinfeldt et al. 2011b). The present work is underpinned by a social identity perspective which encompasses social identity theory (SIT: Tajfel 1978, 2010; Tajfel and Turner 1979; Turner and Tajfel 1986) and self-categorization theory (SCT: Turner et al. 1987). According to the social identity perspective, individuals develop two principal identities: a personal self, which comprises unique, idiosyncratic information about themselves, and a collective self, which comprises information about the groups they belong to (Tajfel 1978). Individuals implicitly construct a multitude of social groupings which are not static but evolve progressively over time (e.g. women, footballer, netballer). For each group, individuals identify common beliefs, attitudes, feelings, and behaviours, known as prototypes (or norms) which differentiate their own group from others (Reid and Hogg 2005). Once an individual can delineate their group(s) unequivocally, they know which prototypes or norms to follow, reducing uncertainty and alleviating anxiety (Hogg and Mullin 1999). An illustration of this was provided by Caudwell's (2007) work focusing on women's soccer in the UK. Caudwell noted how heteronormative structures could be resisted in a sporting context through the valuing of a muscular/'butch' body shape, and therefore a less feminine physique. While her work focused on an all lesbian soccer team, there was no indication that the valuing of larger body shapes was to do with sexuality, rather it was about functionality, and a preference for more muscular bodies in defensive positions. Within this soccer space it therefore became possible to invert sexual norms. However, Caudwell was cautious in her celebration of this seemingly empowering space for women, concluding that the structures of heteronormativity prevail, in particular in regard to how outside observers (spectators, club officials, some members of the men's teams, etc.) viewed the women who played as 'other'.

Social identity theory (Tajfel 1978, 2010; Tajfel and Turner 1979; Turner and Tajfel 1986) informs an exploration of gender identity and body performances by highlighting the role of three key elements when examining social identification and group behaviour. These are the perceived (1) stability and (2) legitimacy of an ingroup's position in relation to other groups, and the perceived (3) permeability of group boundaries (Ellemers 2012; Tajfel and Turner 1979). This theory proposes that once an individual is categorized in terms of a group membership, they then define themselves in terms of that social categorization, and seek to enhance or maintain self-esteem by positively differentiating their ingroup from a comparison outgroup on some valued dimension. SIT lends itself to the study of gender identity and body 
performances within and outside of sport as it offers predictions about the effects of belonging to a group of low status, and the reactions of groups of high status to threatened status.

Self-categorization theory presents three central propositions that extend SIT by seeking to clarify the distinction between social identity and other aspects of the self-concept. The first proposition is that social identity is the cognitive mechanism that makes group behaviour possible (Turner 1982). Specifically, a process of self-stereotyping (depersonalization) allows those who define themselves in terms of a particular social identity to seek to discover the meaning of the category and then strive to enact that meaning. A second proposition is that the self reflects the operation of a categorization process in which, depending on context, people see themselves as either sharing category membership with others (i.e. a shared social identity - 'us'), or not (Turner 1985). Whether, and which, social identities are activated is dependent on a particular categorization's fit, and a person's readiness to use it (Meân and Kassing 2008; Oakes, Haslam, and Turner 1994). The third proposition is that a shared social identity presents the basis for mutual social influence (Turner 1991). This influence results from co-ordinated behaviours in relation to activities relevant to that identity. Identification with, and conformity to norms shared with others in a particular context enables potentially idiosyncratic views to become socially organized and consensual. Collectively, these three propositions describe the processes that link personal cognitions, perceptions and behaviour to organized collective endeavours (Haslam, Postmes, and Ellemers 2003; Reicher, Spears, and Postmes 1995).

The present comparative study utilized a social identity perspective to examine the negotiations and management practices that occur when aligning body performances to acceptable notions of gender and sexuality. While this practice has been noted in a number of so-called 'masculine' sports, this study extends scholarship in this field by exploring how netball - as a more 'feminine' practice also engages in these negotiations. The application of a social identity perspective helps explore individual's self-categorization and resulting engagement with others by sport type. This is of value, because at present, insufficient is known about the nuanced practices across sports traditionally perceived to be 'masculine' and 'feminine'. Clarification could offer insight into the development of marketing resources and interventions that may encourage the uptake of a more diverse range of sports promotion opportunities among females. Finally, this study also examined the extent to which netballers and footballers share a sense of social identity, and thus how they relate to each other as similar (as both part of self) or different (as self vs. other). In doing so, the authors offer new ways of understanding how athletes construct bodily subjectivities as 'functional' and 'intelligible' in the sporting context but 'unintelligible' in other non-sport settings. This research foci will help extend understanding of gender identity and body functionality as reflected in 'on vs off the pitch' practices (Krane et al. 2004; Russell, 2004Authør)AQ3. To conclude, three research questions are addressed; (1) how does UK society influence body performances and notions of femininity, (2) how does sporting culture influence body performances and notions of femininity, and (3) does body satisfaction fluctuate across sport and non-sport contexts.

\section{Methodology}

It is not possible to determine women's understandings of body performances and femininity in soccer and netball without listening carefully to the stories they tell, the language they use, and the social practices inferred. As Kvale $(1996,1)$ succinctly rationalizes; 'if you want to know how people understand their world and their life, why not talk to them'. The chosen method of the present study was focus groups. This was in view of the interactions they promote in discussing experiences, interpretations and understandings of the world (Kruger and Casey 2014)AQ4. These interactions illustrate common language and social practices. Reflective of real life, focus groups also highlight diversity, disjunctive ideas and multidimensional experiences. This not only allows for multiple readings of the same body to be explored but it also enables researchers to examine the consistencies and contradictions that exist in women's sporting experiences produced in the data (Amis 2005).

\section{Participants}

Thirty-one female participants were recruited from a University based in the West Midlands, UK. All participants were white British undergraduate students aged 18-26 years (Age: $M=22.10, S D=1.94$ ). Participants recruited via convenience sampling, and were members of the University netball and football teams, thus they were known to each other and shared the same sport culture. They were informed of the purpose of the study, their role as participants, and aspects of confidentiality and anonymity. Informed by the three research questions, the present study was concerned with capturing soccer and netball players experiences regarding body performances and femininity with a focus on how these were appropriated or resisted in sport participation. 


\section{Procedure}

The first authors' university granted ethical approval for the undertaking of the research. Participants were allocated to one of four focus groups based on their sports participation (two focus groups per sport), allowing participants to react, agree or disagree and provide further insight into the comments made by other participants (Stewart, Shamdasani, and Rook 2007). Using three focus groups for each sport (five participants per group except for one netball focus group of six) allowed an examination of patterns and trends across groups (Kruger and Casey 2014). The focus groups followed a semi-structured interview schedule which covered three themes of inquiry: (1) UK culture, body image and femininity; (2) sporting culture, body image and femininity, and (3) transiency of body image across sporting and social contexts. Interviews concluded with an opportunity for participants to freely express any other opinions concerning body image or femininity.

A focus group guide was produced that focused on exploring the experiences of women in their chosen sport and how notions of 'femininity' were engaged with. Focus groups were delivered using a conversational tone where athletes' experiences were given prominence. The need to respect the views of others, particularly where there was disagreement, was emphasized to focus group members before the session began. Furthermore, time was taken during focus group sessions to allow discussion of competing as well as similar viewpoints. All participants were given pseudonyms. Focus groups lasted between 45 and 90 min, were audio-recorded and transcribed verbatim resulting in 148 pages of singlespaced text.

\section{Data analysis}

The researchers read and re-read the transcripts to immerse themselves in the data, and commentaries were recorded of repeating patterns specific to each research question (Esterberg 2002). Three broad themes resulted from data analysis reflective of the research questions, these being; (1) UK culture, body performances and femininity, (2) sporting culture, body performances and femininity and (3) transiency of body satisfaction across sport and non-sport contexts.

In an attempt to ensure trustworthiness of theme content, authors coded transcripts independently with results compared during Skype and face-to-face meetings. Discussions resulted in either consensus regarding theme content, or changes until consensus was attained. While authors use the term 'soccer', participants utilize the culturally grounded term 'football' in focus group data; however, in the present study both terms describe the same sport.

\section{Results and discussion}

\section{How does UK society influence body performances and notions of femininity?}

Although the focus of this study is the comparison between the cultures of football and netball and how these cultures in turn influence performances of femininity, it is important to recognize that wider societal expectations of femininity are also at play. In addition, a wider consideration of feminine norms associated with UK culture helps provide some wider context for the subcultures of the two sports and the extent to which they are congruent or incongruent with these expectations.

McRobbie (2008) suggests that the restrictions imposed on girls and women regarding their body shape and visual appearance have become a new source of judgment for young women. As such, women are encouraged to self-survey and compare their body to a perceived norm(Carlson 2010)AQ5. In addition, the same standards of judgement are used to survey others. It was clear that participants from both sports were aware of the expectations of femininity, particularly with regards to a normative female body and feminine appearance. In Western society, including the UK, a slender toned body is the ideal that women are encouraged to strive for in all contexts (McRobbie 2008). The desire for portraying a slender body is consistent with previous literature that has highlighted how femininity is reinforced through women's diminutive physical presence and under developed musculature (Knapp 2014). Participants perceived thinness as a particularly desirable trait particularly in terms of signifying femininity (Krane et al. 2004). Louise, a netball player notes: It's definitely like on the slender feminine kind of thing ... that's what people look for. In addition, Mary highlighted that the ideal female has 'long legs and a small waist'.

The media were frequently cited as influential in fuelling body concerns in women through criticisms of bodies that were seen as too large. Consistently, literature examining the portrayal of female athletes in the media has highlighted 
trends of sexualization and the emphasis on a desirable body rather than athletic achievement (Crossman, Vincent, and Speed 2007). As such, the media feed into processes of policing norms of femininity and the feminine body (Bishop 2003). The media were seen to engage in a process of public shaming of celebrity figures for their lack of body discipline and management. Natasha states that:

With size, it's always put in your face because like there's been in the Sunday magazine or something the other day it's about famous people and they say oh what size are you and they claim that they are a size eight or a size twelve and then they'll (media) take a photo of them on a bad day and they will be like no you're a size fourteen, so really they ... the media is always looking to slate people for their figures and to criticise people.

Criticism of women's bodies by the media made the participants more aware of their own bodies and encouraged them to compare themselves to others. The body and appearance was a constant source of anxiety, particularly for the netball players, leading to attempts to survey and modify themselves in accordance with feminine norms (Hendley and Bielby 2012).

Lucy stated that 'you look at yourself and you think I want to be that size or I want to be that shape'. A similar point was made by Louise in the statement that 'you just compare them, you do judge your own body on others'. The desire to conform to these standards led to an ongoing process of scrutinizing personal appearance and engaging in practices to address any perceived imperfections. The constant dissatisfaction with appearance was evident in the following suggestion by Natasha:

I'm constantly wishing to change my appearance. Even on a good day. I would still think I can do this a little bit more

Natasha perceives an ideal appearance to be something just out of reach. The constant dissatisfaction therefore leads to a perpetual cycle of body surveillance and modification. It is plausible to consider that netball, as a sport, is different to that of football in terms of its presentation of the body. Netball players typically wear all in one body suits that are tight fitting and thus expose the body to a spectator (male) gaze more easily, and this may contribute to feelings of body concern that might not be experienced in the same way as the footballers in the present study. The pervasive influence of sport uniform on body concern has previously been evidenced. For example, Th $\square$ gersen-Ntoumani et al. (2011) demonstrated that wearing tight/revealing exercise attire heightened physically active female university students' levels of self-objectification. Furthermore, while footballers did talk about body concern, participants suggested (as discussed later) that netballers are likely to have more 'attention' from males who may have more traditional views of femininity.

Consistent with previous studies, wearing make-up and dressing in a certain way were mechanisms through which females in the study aimed to improve their appearance and perform femininity appropriately (Caudwell 2003; Ezzell 2009; Russell, 2004Auther). They appeared to hold the belief that body preoccupation was something more aligned with femininity, perhaps due to the modification tools available.

With girls no matter what happens, you can always make yourself look better because there is make up and you can wear certain things. (Louise - netball)

The drive to monitor and sculpt the body was reinforced through the normalizing of the body project (Markula and Pringle 2006). This point was perhaps illustrated best by Rebecca (netball) who referred to women's body preoccupation as 'normal': 'it's just a normal part of life, they [women] want to look as good as they can'. Rebecca clearly articulates how Turner's (1985) notion of a shared social identity is enacted here; it encompasses all women rather than just the netballers.

\section{How does sporting culture influence body performances and notions of femininity? Netball}

From a social identity perspective, in the present study, it is possible to recognize in data the evolving of social groupings for netballers; from women (in general) to netball (specifically) (Reid and Hogg 2005). Here, we can see the extension of wider common beliefs regarding the naturalness of body comparison towards the embedding of these practices in the netball subculture. Perhaps unsurprisingly the labelling of netball as a 'girly girl' sport somewhat protected participants from negative stereotyping. Being considered as 'girly girls' and 'pretty girls' allowed the netballer players to retain their femininity in a sporting setting. Players consistently embraced the label of girly associated with 
their participation in netball (Hardy 2015). Louise for instance acknowledged that being seen as a girly girl 'is not a bad thing' as she 'benefits from it in a way' implying netball, as a sport, produces feminine norms and a valued identity both inside and outside of the sport (Jeanes 2011). This behaviour reflects Turner's (1985) 'depersonalisation' process where individuals can find meaning based on their group categorization. For netballers such as Louise, there is shared 'us' here that has associated benefits in conforming to the norms of what it is to be a netballer (in presenting a very gendered physical and social performance) and embracing the perceptions of others about what being a 'girly girl' implies.

Mary described the netball team image as 'lady like' and that was how she believed the players were viewed by others. 'Like the short skirts and stuff ... because the majority of the netball team are like that then that's the way they see the netball girls'. Hendley and Bielby (2012) have suggested that clothing can facilitate identity construction. By choosing certain clothes, in this instance, clothing that is associated with femininity, the players perhaps seek to express who they are and also who they are not. The assumption of netball as a feminine sport was one of the reasons some players were drawn to the sport in the first place. Christina for instance states that 'out of lots of sports in school, that's [netball] like the most feminine'.

For the netball players, a clear process of feminine socialization was apparent. As part of the socialization process, females that joined the netball team were expected to engage in certain feminine behaviours in order to 'fit in' and prove their femininity. Legitimate forms of behaviour (and the resultant bodies) were produced through the normalizing practices of critique. During a discussion about musculature, two players reflected on how a team mate was self-critical of her physique. The discussion also presented the view that others, including themselves (indicated by dialogue and Natasha's use of inflection) were complicit in accepting that the critique was valid:

Natasha: She has got really broad shoulders ... she is really muscular ...

Mary: Like I say to her oh God you are really toned and stuff and she will say 'oh but I'm too muscular' and she does refer to herself as being too muscular.

Natasha: And in all honestly people have said like when we have gone out people have said 'oh she's got ... she's really [emphasised] muscly'.

These judgements based on the perceived excessive musculature of a player, are typical of ways in which bodily norms are established and policed. It also reflects how some individuals activate a particular social identity (here, being critical of a muscular body) in order to mitigate any challenge to their own femininity. Krane et al. (2004) have previously discussed the paradox faced by female athletes when attempting to balance sporting and feminine identities. According to Mosewich et al. (2009), female athletes displaying excessive musculature are challenged by societal and personal expectations which limit their muscular potential. By managing musculature, female athletes are able to maintain a body shape that is consistent with the culturally normative body.

Rookie players were introduced to subcultural expectations early on, and learnt what was acceptable and unacceptable from the more established players. Mary points out that there are certain expectations in terms of producing a look that netballers are expected to adhere to. For this team in particular, players were expected to have their hair done, wear make-up and put moisturiser on prior to a game. 'We have all got our moisturisers on our legs, our hairs done ... do you know what I mean our make- up...'. Hair and beauty are considered important in the construction of femininities (Collins 2005). Engaging in beauty practices as described by players, alongside their sport participation allowed them to manage their identity (Halbert 1997).

Social identity theory is useful here because it predicts that once players are familiar with subcultural expectations, they are able to self-police in accordance with these norms. We suggest that there is a legitimacy given to practices such as those identified above when originating from an ingroup position in comparison to others (rookies to more established players; netballers to other sports). The present study also illustrates how players martial the group boundaries of these practices (Ellemers 2012; Tajfel and Turner 1979). For example, Mary describes how participants copy prevailing behaviours in order to fit in.

If somebody was to come in ... they might try and do those things to fit in with the way we are and stuff ... like moisturising your legs and stuff ... like some girls on our team were like 'I don't do that before I play' but then they started doing it cause we all do it and stuff. 
The netball players appeared not to feel conflicted about their gendered and athletic identities, and managed to balance their need to appear feminine with their participation in sport. This involved conscious efforts to look good while playing. This was illustrated by Natasha who notes that 'I still put foundation on when I go and play sport'. Louise, also described how she and likeminded teammates 'make ourselves look better in a subtle way' when playing sport.

The reward for successful self-policing and the management of feminine and sporting identities was not only to be accepted within the culture, but also to gain the approval of male spectators. Louise highlighted that netballers tend to be spared the detrimental comments they had seen aimed at female footballers, presumably based on the netballers conforming to feminine norms. Identity management in relation to feminine norms has been described by some as a form of cultural capital that is used by female athletes to have their sport participation accepted by friends, family and potential boyfriends (Davis-Delano, Pollack, and Vose 2009; Thorpe 2008).

They have been to watch the girls play football and the majority of the girls they will be like making comments, detrimental comments to them really like ... whereas they wouldn't say anything detrimental to the netball girls.

As well as defining themselves in relation to each other and the norms within the netball culture, players were also keen to distance themselves from what they were not. Turner (1985) would argue that this helps to shape the 'us' within the team/sport and to determine who is not part of that group. Traditionally male sports such as football and rugby were often used as a comparison to highlight their own femininity. Louise for instance stated 'we are completely different to the rugby girls'. Another netball player Bella, elaborated on this comment with the suggestion that:

I think in terms of like netball you have the slender tall figure whereas women rugby players are quite butch, broad, got to be ready sort of thing, footballers are all stereotypes of being like butch.

By the othering of the different sports that they mentioned, they align netball with being feminine and therefore acceptable, and other sports as masculine and therefore unacceptable. Caudwell (2011) has argued that women are not only oppressed by men but also other women. Putting down females who do not conform to norms of femininity or heterosexuality forms part of a female apologetic and identity management strategy. Festle $(1996,256)$ sees such behaviours as detrimental to the development of women's sport allowing 'sexist stereotypes and sexist assumptions to continue rather than insisting there is nothing wrong with female athletes'.

It was not only on the field that the netballers commented on the difference between themselves and players of other sports. Mary also observed some key differences between the netballers and the footballers in social settings, stating that:

Some of the netball girls wouldn't put make up on and stuff but in a way they still had their hair done and they have still got little shorts and a top on but whereas the football girls ... in girls football none of them would wear make-up, none of them would do their hair they are all in like baseball caps.

Mary appears to allude to the difference between the amount of effort that is put in to looking feminine on a night out. The refusal to manage femininity in a social setting is used to mark out difference between football players and netballers. What Mary is also presenting is a way in which she (and other netball players) creates a shared social identity for the netball players and footballers based on a mutual social influence (Turner 1991). This helps shape behaviour in relation to any given context. For example, when describing going out as the netball/football team, Mary seeks to normalize their own activities and the activities of 'other' others (Krane et al. 2004).

\section{Football}

Across the three football focus groups there was consistent suggestion that football tends to be seen as a masculine appropriate activity and consequently female players are likely labelled negatively. In contrast to the netballers who did not believe there to be an issue balancing their sporting interests with their feminine identity, the footballers highlighted the commonly held assumption that playing football and maintaining a feminine identity are incompatible. Many players were keen to stress however that this is an outsider perspective based on gender stereotyping of the sport rather than necessarily reflecting the lived reality. Beverley for instance stated 'I play football and I am perceived to be masculine like in some ways just because I play football, not because I am, just because I play football'. Beverley is clearly highlighting how she is perceived as being masculine based solely on her sport participation and deep-seated stereotypes surrounding women's football in a UK context. The notion of football as masculine was also picked up on by Heidi who suggested how the masculine labelling of the sport is linked to the stereotyping of players as 'butch'. A mannish/lesbian 
stigma continues to be an effective way of maintaining social control and self-monitoring (Davis-Delano, Pollock, and Vose 2009).

I think football, women's football has, has always been stereotyped as a men's game and a lot of females are stereotyped as having to be butch and short hair and stuff just because they play football.

The deliberate distancing from a butch or lesbian stereotype employed by many of the players within the study perhaps indicates just how strong a mechanism of self-policing is at play. The footballers appeared to be resentful of the blanket labelling of everyone taking part in the sport as masculine and butch and they discussed the potential issues of stereotyping. The football players were aware of examples whereby potential new recruits had been anxious about joining a football team based on masculine labelling, and more specifically, a perceived link to homosexuality. This was illustrated by Lea:

Like we had that little dancer join our football team but she didn't join for ages. She was really worried about coming to join because of people's stereotypes and what she's heard off other people, but then she decided to come just to see if it was true.

Lea here alludes to the reputation of football deterring women from playing the game for fear of being stereotyped. According to Malcolm (2003), athletes are frequently motivated by the fear of being perceived as too masculine, and consequently being labelled as butch or lesbian. Conversely, Chase (2006) observed that sport can provide a safe space for the construction of alternative femininities. A similar trend was highlighted by Caudwell (2011), who even suggested that in some instances, football provided a space for gendered norms to be inverted. She did however acknowledge that while there are opportunities for resistance, these are likely to be limited, and that structures of heteronormativity prevail and the data in this study attest to that. Although the players in this study discussed team mates who they felt resisted conventional norms of femininity, this was not viewed as something to be celebrated. Instead these players were perceived negatively because they fit the stereotype associated with the sport that the players in this study were desperate to avoid.

In contributing to focus group discussions on this topic, Alexa appears to imply that the inherent norms within football, presumably linked to the sport's masculine traits, potentially influence the degree to which participants engage with femininity. Rather than offering support for alternative femininities, Alexa was critical of others who chose to 'reject' conventional notions of feminine ideals.

I think like some football girls ... as they have grown up they have been influenced by football and so now they just don't care about themselves, don't make any effort with themselves; they have put weight on and they just don't care about themselves any more, they don't make any effort and I think that they are influenced by that culture of football because it is seen as a butch sport.

Consistent with Caudwell's (1999) findings, heterosexual players frequently resented the 'butch' label attached to their sport participation and this led to homophobic attitudes and judgement of other players who did not conform to feminine and heterosexual norms. The following conversation between Melanie and Alexa highlights the assumption that the butch body is valued in a sporting context:

Melanie: There is a certain player that plays with us I think that like she has gone towards the stereotype to try and fit in with the football team ... she does put on a butch persona and that's so that she can fit in.

Alexa: I mean an example of someone whose body has changed is you know Blondes. When she first came to Uni she was like really thin, really attractive always made an effort and know I think she has been playing football for three years and now you see her and, I am not saying that she doesn't make any effort anymore, but just saying that she has been affected obviously by some of the footballers because her body image has completely changed. She doesn't make half as much effort, she has put on a bit of weight and I think that has been affected by football.

Alexa continued her belief that many footballers deliberately created an environment where only 'legitimate' (butch) bodies were valued:

I feel that some of the footballers [female] look at me as if to say you are a bit too much of a girly girl to play football you need to be a bit more of a man, more butch, like when I go out. Most of them are all butch and lesbians, I am different, in a sense I feel isolated because I am not like that, I am not the norm. 
She was keen to indicate that this perception of a need to resist a butch identity was shared by others;

I have a friend ... just started this year and she has joined the football team and they are all butch lesbians and really bad and she has gone out of her way to prove that she is not a lesbian and she was like, they were like all sort of questioning her what she was and now she like goes out of her way to be feminine, to be girly, because she doesn't want them thinking that she is going to change

Alexa felt that within soccer, body presentation and 'management' was necessary to maintain a clear identity for her (personal self) and some of her (heterosexual) friends as a feminine heterosexual female. For Alexa this meant a direct resistance to the perceived value of the butch body by existing footballers (collective self) (Tajfel 1978) within the team. Alexa has constructed her own set of prototypes (norms) in relation to beliefs, attitudes and behaviour to help her differentiate her own group from others (Reid and Hogg 2005). In contrast to participants in Caudwells' (2007) study on an all lesbian football team who rejected heteronormative structures of the game to be less feminine, Alexa shows how she deliberately and actively rejects the 'masculinising' of the female footballer in her team.

In contrast to the consistency regarding acceptable boundaries of femininity in netball, there appeared to be a divided culture in football with two different sets of norms operating in parallel, but being in a state of tension. Football players frequently discussed internal conflict within the sporting subculture regarding appropriate gendered performances. Those players who reject conventional norms of femininity are at risk of being labelled both inside and outside the culture as butch and presumably homosexual, while those players deemed to be 'too feminine' felt that they might be rejected within the culture but being overtly 'feminine' helped them to avoid labelling in wider society. Krane et al. (2004) previously suggested that in the process of negotiating and reconciling the social expectations of femininity with athleticism, sports women develop two identities - athlete and woman. Within this particular team, there were perceived differences in the management of these two potentially conflicting identities.

\section{Does body satisfaction fluctuate across sport and non-sport contexts?}

Body satisfaction appeared at least to some extent to fluctuate across sporting and non-sporting contexts. Consistent with previous literature, a common focus of discussions about body satisfaction transiency across sporting and nonsporting settings was muscularity (Krane et al. 2004; Steinfeldt et al. 2011a). The development of a muscular physique was a particular concern despite recognizing that it is perhaps an inevitable consequence of training and participating in sport (Sisjord and Kristiansen 2008)AQ6. Participants consistently expressed the belief that cultural norms dictate it is unfeminine to possess a muscular physique and the fear attached to that presentation, particularly outside of a sporting context. Footballer Nicola suggests that:

You want to be muscular and you want to be that for your sport but then obviously when you go out into society, you're not in the sporting surroundings so you look kind of out of place ... I think the things that benefit your sport might not necessary benefit your social life.

A similar point was raised by netballer Carol about feeling more conscious about a sporting body in a social setting.

Yeah, I agree, because you want to come across as a sporty person when you are playing the sport, you want to look toned you want to look fit, and then when you are out and about you don't want people to think, that you are a bit too muscularly or a bit butch.

It appeared that the fear of becoming overly muscular and being judged in a social context manifested itself in the deliberate avoidance of activities to protect against muscle development; 'I go to the gym twice a week but I tend to stay clear of the weights in fear of getting really big, bulky muscles that look really unattractive' (Beverly, soccer). These body management behaviours (Caudwell 2003; Cox and Thompson 2000, 2001; Dworkin 2003, Halbert 1997; Russell, 2004Author) demonstrate the body critiquing/regulating practices that ensure the continuation of sportswomen self-policing.

Height for the netballers was also discussed as being advantageous for the sport, particularly for certain positions, but something that also marked players out from the norm in a social context. Netballer Lucy discussed how she perceived her height inside and outside of a sporting context.

Like personally, like in sport I think I am pleased with my height I am not generally I don't mind I like being tall my whole family is tall and I have always been surrounded my tall people but then I go and play netball and there is not many people I come against that are tall then me so that is one major advantage to 
me like and I do love my height I love being this tall but then I go out and the problem like with ... like going out with you and Helen you are all like five foot and a bit and I am like nearer enough coming up to six foot ... so sometimes I feel too tall.

Participants frequently discussed the privileging of femininity in a social context compared to in a sporting context. The need to appear feminine for Mary was linked to an increased self-awareness in an environment where there are 'guys about'.

Mary: Like some people say, like John will say to me, 'god you look like two different people from the day to the night', like you are transforming to the night.

Lucy: You are more aware of your image, well I feel I am more aware in a social context then in a sports context.

A limitation of the present study was arguably the use of convenience sampling. Once it was known who early volunteers were, other members of the University sports teams may have declined participation. This suggestion is based on the absence of an alternative voice in the soccer focus groups. While Alexa (soccer), noted that 'most of them [the soccer team] are all butch and lesbians', a non-hetero-normative perspective was absent from the focus group data. Seemingly, lesbian soccer players chose not to partake in the focus groups, or, if they did, they chose not to self-disclose. We did not ascertain participant's sexuality during the present study, and would advocate that future research should do so. This should be done in such a way that confidentiality is maintained as desired, and this may require the use of individual interviews as opposed to focus groups. A further limitation of the present study is the absence of racial diversity. We would advocate further research examines the intersectionality of race, ethnicity and sporting cultures when examining gendered performances and identity construction. For example, previous research has found that body image disturbance is lower among females from ethnic minorities compared to their white counterparts (Hausenblas and Symons Downs 2001).

To conclude, the present study illustrates the way in which individuals were subject to social interpretation and judgement, particularly football players. Involvement in football, and the actual or perceived presence of lesbian sexuality, was seen to affect player's identities, perceived sexuality, and associated behaviours; in effect producing a negotiated gendered performance (Author; Caudwell 2007; Ravel and Rail 2006; Russell, 2004; Shogan 1999). Female soccer players in the present study were more likely to face questions about their own or team-mates sexuality, and experienced a range of perceived pressures to conform to a feminine appearance on one hand, or a legitimate butch body on the other.

The labelling of netball as a 'girly' sport somewhat protected players from social judgement. Players were able to reconcile both a sporting and feminine identity more easily than their football counterparts. Participants did however engage in regular policing of feminine norms and the encouragement of feminine practices through the process of socialization into the sport.

Comparing the sports of netball and football with their differing cultural history, and associated pre-conceptions and stereotypes, has helped illuminate the influence of sporting subcultures on gendered performances and identity construction. This research also develops understanding of the ways in which female athletes engage in identity management strategies. We argue that while women have pursued sporting participation across gendered lines, it remains important to be critical of those practices that continue to maintain difference and limit the range of possibilities for sportswomen to be feminine and masculine alike. In drawing practical implications from this research, we advocate that in seeking to market sports participation to women (e.g. sport governing bodies), a wider range of imagery is showcased when marketing female sports, so as to disrupt the idea that there is one ideal form of femininity.

\section{Disclosure statement}

No potential conflict of interests was reported by the author(s).AQ7

\section{References}

Amis, J. 2005. “Interviewing for Case Study Research.” In Qualitative Methods in Sports Studies, edited by D. L. Andrews , D. S. Mason, and M. L. Silk , 104-139. Oxford: Berg. 
Bennett, E. V., L. Scarlett, L. Hurd Clarke, and P. R. Crocker . 2017. "Negotiating (Athletic) Femininity: The Body and Identity in Elite Female Basketball Players." Qualitative Research in Sport, Exercise and Health 9: 233-246. doi: 10.1080/2159676X.2016.1246470

Bishop, R. 2003. "Missing in Action: Feature Coverage of Women's Sport in Sports Illustrated.” Journal of Sport and Social Issues 27: 184-194. doi:10.1177/0193732502250718

Burroughs, A., and J. Nauright . 2000. "Women's Sports and Embodiment in Australia and New Zealand.” The International Journal of the History of Sport 17: 188-205. doi:10.1080/09523360008714133

Caudwell, J. C. 1999. "Women's Football in the United Kingdom Theorizing Gender and Unpacking the Butch Lesbian Image." Journal of Sport and Social Issues 23: 390-402. doi: 10.1177/0193723599234003

Caudwell, J. C. 2003. "Sporting Gender: Women's Footballing Bodies as Sites/Sights for the (Re)Articulation of Sex, Gender and Desire." Sociology of Sport Journal 20: 371-386. doi: 10.1123/ssj.20.4.371

Caudwell, J. C. 2007. "Queering the Field? The Complexities of Sexuality Within a Lesbian-Identified Football Team in England, Gender, Place and Culture." A Journal of Feminist Geography 14: 183-196. doi:

$10.1080 / 09663690701213750$

Caudwell, J. 2011. “Gender, Feminism and Football Studies.” Soccer and Society 12: 330-344. doi: 10.1080/14660970.2011.568099

Chase, L. F. 2006. “(Un)Disciplined Bodies: A Foucauldian Analysis of Women's Rugby.” Sociology of Sport Journal 23: 229-247. doi: 10.1123/ssj.23.3.229

Choi, P. 2000. Femininity and the Physically Active Women. London: Routledge.

Christopherson, N., M. Janning, and E. McConnell . 2002. “Two Kicks Forward, One Kick Back: A Content Analysis of Media Discourses on the 1999 Women's Championship.” Sociology of Sport Journal 19: 170-185. doi: 10.1123/ssj. 19.2.170

Collins, P. 2005. Black Sexual Politics: African Americans, Gender, and the New Racism. New York, NY: Routledge.

Cooky, C., and M. McDonald . 2005. "If You Let Me Play”: Young Girls’ Insider-Other Narratives of Sport.” Sociology of Sport Journal 22: 158-177. doi: 10.1123/ssj.22.2.158

Cox, B., and S. Thompson . 2000. "Multiple Bodies: Sportswomen, Soccer and Sexuality." International Review for the Sociology of Sport 35: 5-20. doi: 10.1177/101269000035001001

Cox, B., and S. Thompson . 2001. "Facing the Bogey: Women, Football and Sexuality.” Football Studies 4: 7-24.

Crossman, J., J. Vicent , and H. Speed . 2007. “The Times they are a Changing': Gender Comparisons in 3 National Newspapers of the 2004 Wimbledon Championships." International Review for the Sociology of Sport 42: 27-41. doi: $10.1177 / 1012690207081828$

Davis-Delano, L. R., A. Pollack , and J. Vose . 2009. “Apologetic Behavior among Female Athletes.” International Review for the Sociology of Sport 44: 131-150. doi: 10.1177/1012690209335524

Dworkin, S. L. 2003. "Holding Back: Negotiating a Glass Ceiling on Women's Muscular Strength.” In The Politics of Women's Bodies: Sexuality, Appearance, and Behaviour, edited by R. Weitz, 240-256. New York, NY: Oxford University.

Ellemers, N. 2012. “The Group Self.” Science 336: 848-852. doi:10.1126/Science.1220987.

Esterberg, K. G. 2002. Qualitative Methods in Social Research. Toronto, Canada: McGraw-Hill.

Ezzell, M. B. 2009. “'Barbie Dolls’ on the Pitch: Identity Work, Defensive Othering, and Inequality in Women's Rugby.” Social Problems 56: 111-131. doi:/10.1525/sp.2009.56.1.111

Fasting, K., and C. Brackenridge . 2009. “Coaches, Sexual Harassment and Education.” Sport, Education and Society 14: 21-35. doi: 10.1080/13573320802614950

Festle, M. J. 1996. Playing Nice: Politics and Apologies in Women's Sports. New York, NY: Columbia University Press. 
Guillet, E., P. Sarrazin , P. Fontayne , and R. Brustad . 2006. "Understanding Female Sport Attrition in a Stereotypical Male Sport within the Framework of Eccles's Expectancy-Value Model.” Psychology of Women Quarterly 30: 358368. doi: 10.1111/j.1471-6402.2006.00311.x

Halbert, C. 1997. "Tough Enough and Woman Enough: Stereotypes, Discrimination, and Impression Management Among Women Professional Boxers.” Journal of Sport and Social Issues 21: 7-36. doi: 10.1177/019372397021001002

Hardy, E. 2015. “The Female 'Apologetic' Behaviour Within Canadian Women's Rugby: Athlete Perceptions and Media Influences.” Sport in Society 18: 155-167. doi: 10.1080/17430437.2013.854515

Haslam, S. A., T. Postmes , and N. Ellemers . 2003. "More than a Metaphor: Organizational Identity Makes Organizational Life Possible.” British Journal of Management 14: 357-369. doi:10.1111/J.1467-8551.2003.00384.X

Hausenblas, H. A., and D. Symons Downs . 2001."Comparison of Body Image Between Athletes and Non-Athletes: A Meta-Analytic Review." Journal of Applied Sport Psychology 13: 323-339. doi: 10.1080/104132001753144437

Hermann, J. M., and R. Vollmeyer . 2016. “Girls Should Cook, Rather Than Kick!”-Female Soccer Players under Stereotype Threat.” Psychology of Sport and Exercise 26: 94-101. doi: 10.1016/j.psychsport.2016.06.010

Hendley, A., and D. D. Bielby . 2012. "Freedom Between the Lines: Clothing Behavior and Identity Work Among Young Female Soccer Players.” Sport, Education and Society 17: 515-533. doi: 10.1080/13573322.2011.608950

Hogg, M. A., and B. Mullin . 1999. "Joining Groups to Reduce Uncertainty: Subjective Uncertainty Reduction and Group Identification." In Social Identity and Social Cognition, edited by D. Abrams and M. A. Hogg. Oxford: Blackwell.AQ8

Jeanes, R. 2011. “'I'm into High Heels and Make Up But I Still Love Football': Exploring Gender Identity and Football Participation with Preadolescent Girls.” Soccer and Society 12: 402-420. doi: 10.1080/14660970.2011.568107

Knapp, B. A. 2014. "Gender Representation in the CrossFit Journal: A Content Analysis.” Sport in Society 18: 688703. doi: 10.1080/17430437.2014.982544

Krane, V., P. Y. L. Choi , S. M. Baird , C. M. Aimar , and K. J. Kauer . 2004. "Living the Paradox: Female Athletes Negotiate Femininity and Muscularity." Sex Roles 50: 315-329. doi:10.1023/B:SERS.0000018888.48437.4f

Kruger, R. A., and M. A. Casey . 2014. Focus Groups: A Practical Guide for Applied Research. Thousand Oaks, CA: Sage.

Kvale, S. 1996. Interviews: An Introduction to Qualitative Research Interviewing. Thousand Oaks, CA: Sage.

Malcolm, N. L. 2003. "Constructing Female Athleticism: A Study of Girls' Recreational Softball.” American Behavioral Scientist 46: 1387-1404. doi: 10.1177/0002764203251479

Markula, P., and R. Pringle . 2006. Foucault, Sport and Exercise: Power, Knowledge and Transforming the Self. London: Routledge.

McRobbie, A. 2008. The Aftermath of Feminism. London: Sage.

Meân, L. J., and J. W. Kassing . 2008. “'I Would Just Like To Be Known As An Athlete': Managing Hegemony, Femininity, and Heterosexuality in Female Sport.” Western Journal of Communication 72: 126-144. doi: $10.1080 / 10570310802038564$

Mosewich, A. D., A. B. Vangool , K. C. Kowalski , and T. L. F. McHugh . 2009. "Exploring Women Track and Field Athletes' Meanings of Muscularity." Journal of Applied Sport Psychology 21: 99-115. doi: 10.1080/10413200802575742.

Oakes, P. J., S. A. Haslam, and J. C. Turner . 1994. Stereotyping and Social Reality. Oxford: Blackwell.

Ogunniyi, C. 2013. "Perceptions of the African Women's Championships: Female Footballers as Anomalies." Sport in Society: Cultures, Commerce, Media, Politics doi:10.1080/17430437.2013.815516.AQ9

Ravel, B., and G. Rail . 2006. “The Lightness of Being 'Gaie': Discursive Constructions of Gender and Sexuality in Quebec Women's Sport.” International Review for the Sociology of Sport 41: 395-412. doi:

10.1177/1012690207080239 
Reicher, S. D., R. Spears , and T. A. Postmes . 1995. "Social Identity Model of Deindividuation Phenomena.” In European Review of Social Psychology, edited by W. Strobe and M. Hewstone , 161-198. Chichester, UK: Wiley.

Reid, S. A., and M. A. Hogg . 2005. “Uncertainty Reduction, Self-Enhancement, and Ingroup Identification.” Personality and Social Psychology Bulletin 31: 804-817. doi: 10.1177/0146167204271708

Shogan, D. 1999. The Making of High Performance Athletes: Discipline, Diversity and Ethics. Toronto, Canada: University of Toronto Press.

Sisjord, M. K., and E. Kristiansen . 2008. “Serious Athletes or Media Clowns? Female and Male Wrestlers' Perceptions of Media Constructions.” Sociology of Sport Journal 25: 350-368. doi: 10.1123/ssj.25.3.350

Steinfeldt, J. A., H. Carter , E. Benton , and M. C. Steinfeldt . 2011a. "Muscularity Beliefs of Female College StudentAthletes." Sex Roles 64: 543-554. doi: 10.1007/s11199-011-9935-2

Steinfeldt, J. A., R. Zakrajsek , H. Carter, and M. C. Steinfeldt . 2011b. "Conformity to Gender Norms among Female Student-Athletes: Implications for Body Image.” Psychology of Men and Masculinity 12: 401-416. doi:10.1037/ a0023634

Stewart, D., P. Shamdasani , and D. Rook . 2007. Focus Groups: Theory and Practice. 2nd ed. Thousand Oaks, CA: Sage.

Tajfel, H. 1978. Intergroup Behavior. Introducing Social Psychology. New York, NY: Penguin Books.

Tajfel, H. 2010. Social Identity and Intergroup Relations. Cambridge: Cambridge University Press.

Tajfel, H., and J. C. Turner. 1979. “An Integrative Theory of Intergroup Conflict.” In The Social Psychology of Intergroup Relations, edited by W. G. Austin and S. Worchel , 33-47. Monterey, CA: Brooks-Cole.

Taylor, T. 2004. "The Rhetoric of Exclusion: Perspectives of Cultural Diversity in Australian Netball." Journal of Sport and Social Issues 28: 453-476. doi:10.1177/0193723504269881

Treagus, M. 2005. "Playing Like Ladies: Basketball, Netball and Feminine Restraint." The International Journal of the History of Sport 22: 88-105. doi: 10.1080/0952336052000314593

Th $\square$ gersen-Ntoumani, C., N. Ntoumanis , J. Cumming , K. J. Bartholomew , and G. Pearce . 2011. "Can Self-Esteem Protect Against the Deleterious Consequences of Self-Objectification for Mood and Body Satisfaction in Physically Active Female University Students?" Journal of Sport and Exercise Psychology 33: 289-307. doi: 10.1123/jsep. 33.2.289

Thorpe, H. 2008. "Foucault, Technologies of Self, and the Media: Discourses of Femininity in Snowboarding Culture." Journal of Sport and Social Issues 32: 199-229. doi: 10.1177/0193723508315206

Turner, J. C. 1982. “Towards a Cognitive Redefinition of the Social Group.” In Social Identity and Intergroup Relations, edited by H. Tajfel , 15-40. Cambridge: Cambridge University Press.

Turner, J. C. 1985. "Social Categorization and the Self-Concept: A Social Cognitive Theory of Group Behaviour.” In Advances in Group Processes, edited by E. J. Lawler, 77-122. Greenwich, CT: JAI.

Turner, J. C. 1991. Social Influence. Pacific Grove, CA: Brooks/Cole.

Turner, J. C., and H. Tajfel . 1986. “The Social Identity Theory of Intergroup Behavior.” In Key Readings in Social Psychology. Political Psychology: Key Readings, edited by J. T. Jost and J. Sidanius , 276-293. New York, NY: Psychology Press.

Turner, J. C., M. A. Hogg , P. J. Oakes , S. D. Reicher, and M. S. Wetherell . 1987. Rediscovering the Social Group: A Self-Categorization Theory. Cambridge, MA: Basil Blackwell. 


\section{Author Queries}

Query: AQ1: Please review the table of contributors below and confirm that the first and last names are structured correctly and that the authors are listed in the correct order of contribution. This check is to ensure that your names will appear correctly online and when the article is indexed.

\begin{tabular}{|l|l|l|l|}
\hline \multicolumn{3}{|l|}{ Sequence Prefix Given name(s) } & Surname Suffix \\
\hline 1 & Tracey J. & Devonport & \\
\hline 2 & Kate & Russell & \\
\hline 3 & Kath & Leflay & \\
\hline 4 & Jennifer & Conway & \\
\hline
\end{tabular}

Response: The authors are presented correctly both in spelling and order

Query: AQ2: The year for "Taylor 2001" has been changed to "Taylor 2004" to match the entry in the references list. Please provide revisions if this is incorrect.

Response: Apologies 2004 is correct, thankyou for noting this

Query: AQ3: Kindly replace the word "Authors" in text with appropriate references, as per style.

Response: Russell, K., M. 2004. \&Idquo; On versus off the pitch: The transiency of body satisfaction among female rugby players, cricketers, and netballers.\&rdquo; Sex roles, 51: 561-574. doi: 10.1007/s11199-004-5466-4

Query: AQ4: The year for "Kruger and Casey 2000" has been changed to "Kruger and Casey 2014" to match the entry in the references list. Please provide revisions if this is incorrect.

Response: Thank you again for correcting this error

Query: AQ5: The reference "Carlson 2010" is cited in the text but is not listed in the references list. Please either delete the in-text citation or provide full reference details following journal style

Response: This refernece has been deleted as suggested

Query: AQ6: The year for "Sisjord and Kristiansen 2009" has been changed to "Sisjord and Kristiansen 2008" to match the entry in the references list. Please provide revisions if this is incorrect.

Response: M any thanks, this ammendment is correct

Query: AQ7: The disclosure statement has been inserted. Please correct if this is inaccurate.

Response: This is an accurate discolsure statement

Query: AQ8: Please provide page number for Hogg and M ullin (1999).

Response: the page numbers are 249-279

Query: AQ9: Please provide volume number and page number for Ogunniyi (2013).

Response: this is volume 17 , pages $537-549$ 